\title{
Hydrophyllaceae endémicas del Perú
}

Blanca León ${ }^{1,2}$

${ }^{1}$ Museo de Historia Natural, Av. Arenales 1256, Aptdo. 14-0434, Lima 14, Perú

2 Plant Resources Center, University of Texas at Austin, Austin TX 78712 EE.UU.

blanca.leon@mail.utexas.edu

\section{Resumen}

La familia Hydrophyllaceae es reconocida en el Perú por presentar cuatro géneros y siete especies (Brako \& Zarucchi, 1993), todas hierbas o subarbustos. Una sola especie, del género Wigandia, es reconocida como endémica, la cual ocupa la región Bosques Secos, entre los 1600 y $1800 \mathrm{~m}$ de altitud. No se encuentra representado en el Sistema Nacional de Áreas Naturales Protegidas por el Estado.

Palabras claves: Hydrophyllaceae, Wigandia, Perú, endemismo, plantas endémicas.

\section{Abstract}

The Hydrophyllaceae are represented in Peru by four genera and seven species (Brako \& Zarucchi, 1993), all herbs and subshrubs. One species, in the genus Wigandia, is recognized here as endemic, which grows in Dry Forests region, between 1600 and 1800 $\mathrm{m}$ elevation, and has not yet been collected in Peru's protected areas system.

Keywords: Hydrophyllaceae, Wigandia, Peru, endemism, endemic plants.

\section{Wigandia wurdackiana Ferreyra}

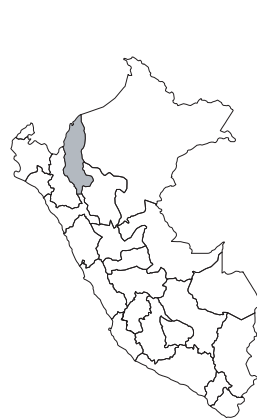

\section{EN, B1a}

Publicación: Biollania, Ed. Esp. No. 6: 328-329. 1997.

Colección tipo: R. Ferreyra 15338

Herbarios: ; USM.

Nombre común: Desconocido.

Registro departamental: AM.

Regiones Ecológicas: BS; 1600—1800 m.

SINANPE: Sin registro.

Herbarios peruanos: USM (holotipo citado).

Observaciones: Arbusto conocido solamente de la cuenca del Marañón, de dos localidades cercanas. El ejemplar tipo, recolectado en la década de 1960, proviene de un lugar dominado por vegetación xérica. El otro ejemplar conocido proviene de los Cerros Calla Calla, en ambientes más mésicos; esta última localidad es conocida por los varios endemismos que alberga. Ferreyra (1997) comenta que el ejemplar de Calla Calla fue reconocido como Wigandia crispa en Brako \& Zarucchi (1993). 